\title{
The Perspectives of Individuals with Cognitive Disabilities and/or Autism on Their Lives and Their Problem Behavior
}

\author{
Michael B. Ruef \\ California Polytechnic State University \\ Ann P. Turnbull \\ The University of Kansas
}

The purpose of the study was 2-fold: (a) to explore the perceptions of individuals with cognitive disabilities and/ or autism regarding barriers and solutions they have experienced related to problem behavior, and (b) to elicit suggestions on areas viewed as most helpful in increasing quality of life while reducing or eliminating problem behavior. A qualitative method of inquiry using focus groups and individual interviews was used. Several themes emerged from the focus groups, including the difficulties participants experienced with communication; participants' need for personal decision making and privacy; and the importance of recreation, employment, selection of living situations, and relationships with friends and family members. The article indicates the importance of listening carefully to individuals with disabilities as a first step in improving the quality of their lives.

DESCRIPTORS: problem behavior, autism, cognitive disabilities, quality of life, participatory action research, focus groups

Individuals with problem behavior, cognitive disabilities, and/or autism place tremendous demands on the support capacities of teachers (Billingsley, Bodkins, \& Hendricks, 1993; Billingsley, 1993; Billingsley \& Cross, 1991; U.S. Department of Education, 1998), families, and other caregivers (Bouma \& Schweitzer, 1990: Koegel et al., 1992; Quine, 1.986; Robbins, Dunlap, \&

Portions of this manuscript were adapted from Ruef, M. (2001). Wie Personen mit Autismus and geistiger Behinderung das eigene Prohlemverhalten sehen-eine qualitative Untersuchung unter Einbeziehung von Fokusgguppen, Heilpädagische Forschung, 27, 158-169. Copyright 2001 by Herbert Goetze. Adapted with permission. For reprints of the German manuscript, contact Prof. Dr. Herbert Goetze, Universatile Potsdam, Institut fair Sonderp5dagogik, Postfach 6012 53, 144115 Potsdam, Germany.

Address all correspondence and requests for reprints to Mike Ruef, California State Polytechnic University, University Center for Teacher Education, Building 2, Room 106, San Luis Obispo, CA 93407. E-mail: mruef@calpoly.edu
Plienis, 1991; Turnbull \& Ruef, 1997). Furthermore, the difficulties of finding solutions to the challenges posed by problem behaviors, in turn, lessens the quality of life for all involved. Until recently, few examples existed in which individuals with problem behavior and cognitive disabilities and/or autism have (a) experienced a significant reduction or elimination of problem behaviors through systematic programming and (b) achieved comprehensive lifestyle change. Carr et al. (1.999) found that lifestyle outcomes (i.e., opportunities to live, work, go to school, recreate, and socialize with typical peers and significant others in typical community settings) were measured for less than $3 \%$ of the 230 research participants involved in research studies between 1985 and 1996. Although progress has been made in addressing a number of lifestyle issues such as family stress, family and individual activity patterns, level of support, and stakeholder satisfaction with intervention plans (Koegel, Bimbela, \& Schreibman, 1996; Koegel et al., 1992; Lucyshyn, Albin, \& Nixon, 1997; Luchyshyn, Olson, \& Horner, 1995; Vaughn, Clarke, \& Dunlap, 1997; Vaughn, Dunlap, Fox, Clarke, \& Bucy, 1997), many instances recorded in the literature describe a failure of the system to provide sufficient support, as well as extraordinary efforts by families to provide reasonable lifestyles for their sons or daughters (DeVault, Krug, \& Fake, 1996; Turnbull \& Turnbull, 1996; Turnbull \& Turnbull, 2000; Turnbull \& Turnbull, 2001).

Although the daily struggles of individuals with problem behavior and those who support them continue, advances have occurred in the ways behavior interventions are approached. Behavioral science now emphasizes a broadened approach to behavioral programming (Carr et al., 2002; Horner, Albin, \& O'Neill, 1996) aimed at more than just focusing on the behavior and those events that immediately precede and follow the behavior (Alberto \& Troutman, 2003). Behavioral scientists have shifted from approaches targeting the individual and his or her behavior in isolation, to a more comprehensive approach. For example, positive behavioral support (PBS) is an applied science that uses educational and systems change 
methods (environmental redesign) to enhance quality of life and minimize problem behavior (Carr et al., 2002). Among the most important issues for a technology of behavioral support is recognition that the standards for assessing "success" are changing. An effective behavioral support plan should integrate procedures for building access to activities, places, people, and events in addition to modifying the patterns of specific desirable and undesirable behaviors (Hitzing, 1988, Horner,1991; O'Brien, 1987). According to Carr et al. (1999), PBS ... "[must] ... build prosocial behavior, document durable change, generalize across a full range of situations and individual encounter[s], and produce access to a rich life style" [italics added] (p. 4).

The importance of providing a sustainable quality of life for more individuals with problem behavior is critical. As Carr et al. (1999) suggest, the way in which success has been measured previously may fall short. of considering quality of life issues. Furthermore, the welldocumented continuing gap between research and practice (Carnine. 1997; Kaestle, 1993; Kaufman, Schiller, Birman, \& Coutinho, 1993; Kornblet, 1997; Billups, 1997; Sydoriak \& Fields, 1997; Morrissey, 1.997; Mitchell, 1997; Malouf \& Schiller, 1995) creates difficulties in providing state-of-the-art interventions. In addition, the gap between research and practice in providing support to individuals with problem behavior lies in the relevance of the research as viewed from the perspectives of individuals with disabilities, their families, and other support persons. Research that is based on the perspectives of persons with more significant disabilities is scarce (Freedman \& Fesko, 1996; Goode, 1986, 1992; Olney, 2001; Ruef, 2001; Schubert; 1997).

In an effort to help bridge the gap between research and knowledge utilization, this study used a participatory action research (PAR) approach, an approach now emphasized in PBS (Carr et al., 2002). PAR emphasizes useful outcomes and collaboration between researchers and intended beneficiaries. One of the most basic elements of PAR is participation by the persons most affected by the phenomenon under study (Bruyere. 1993; Walker, 1993). Constituent participation in every research phase increases the probability that problems are not only identified and solved, but also that solutions are useful and used by constituents (Bruyere, 1993; Meyer, Park, GrenotScheyer, Schwartz, \& Harry, 1998; Markey, 2000; Santelli, Singer, DiVenere, Ginsberg, \& Powers, 1998; Turnbull, Friesen, \& Ramirez, 1998: Whyte, Greenwood, \& Lazes, 1991). Using the PAR methodology, the researchers elicited discussion relating to the perspectives of 9 individuals with cognitive disabilities and/or autism and problem behavior with respect to both the quality of their lifestyles and their problem behavior.
This article, which describes a component of a larger research project (Ruef, Turnbull, Turnbull, \& Poston, 1999; Ruef \& Turnbull, 2001), explored the perspectives of individuals with cognitive disabilities and/or autism, regarding the following research questions: (a) What do you believe are some of the conditions/ harriers that caused the behavioral challenges you have experienced? (b) What do you believe it would take to find solutions to the behavioral challenges you and other persons with cognitive disabilities and/or autism face? (c) What kinds of useful informational products do you believe would be most helpful in building positive, practical solutions to behavioral challenges?

\section{METHOD}

Face-to-face focus groups were the source for data collection. Focus groups were chosen as a method because (a) they provide opportunities for participants to identify and describe issues important to them, and (b) they attempt to create a secure and nonthreatening environment conducive to meaningful interaction, which is especially important for groups such as individuals with disabilities and their families and friends, who his torically have had a limited amount of power and influence (Brotherson, 1994; Krueger, 1994; Marshall \& Rossman, 1995; Maxwell, 1996; Morgan \& Krueger, 1993; Silverman, 1992; Stewart \& Shamdasani, 1990). In addition, individual follow-up interviews were conducted with two participants.

\section{Participants}

The nine focus group participants represented two subgroups: individuals with cognitive disabilities and individuals with autism. In one group, the 5 participants were diagnosed as having cognitive disabilities; the 4 individuals in the second group were diagnosed with autism. Although 2 of these 4 individuals in the second group had difficulties engaging in expressive verbal conversation, none had a clear diagnosis of cognitive disabilities. All, however, received either support services, or funds with which to purchase such services, from state agencies providing services to persons with cognitive disabilities or developmental disabilities. Face-to-face focus groups were conducted with each of the subgroups. Participants represented urban and rural areas of five states, and ranged in age from 24 to 45 years. Six of the 9 individuals were men, and 3 were women. One was African American, and 8 were Caucasian. All of the participants in the focus group comprising individuals with cognitive disabilities lived in houses or apartments operated by a local adult agency. The level of support each of these participants required varied from 2:3 (i.e., 2 staff persons to 3 individuals with disabilities) to $2: 5$ (i.e., 2 staff persons to 5 individuals with disabilities) (Table 1). For 3 of these participants, no staff person was present from 11 p.m. until 6 a.m., although the outside doors were locked 
Table 1

\begin{tabular}{|c|c|c|c|c|c|c|c|c|}
\hline Participant & $\begin{array}{c}\text { Age } \\
\text { (years) }\end{array}$ & Disability & Gender & Ethnicity & Geography & $\begin{array}{l}\text { Demograpl } \\
\text { Living } \\
\text { situation }\end{array}$ & $\frac{\text { cs }}{\text { Level of support }}$ & $\begin{array}{l}\text { Receptive/expressive } \\
\text { language }\end{array}$ \\
\hline 1 & 38 & Autism & $\mathrm{F}$ & White & $\begin{array}{c}\text { MI/city, } \\
110,000\end{array}$ & Independent & Independent & $\begin{array}{l}\text { Answered in sentences; indirect verbal prompts } \\
\text { required: spontaneous comments made }\end{array}$ \\
\hline 2 & 25 & Autism & $\mathrm{F}$ & White & $\begin{array}{l}\text { MA/town, } \\
\quad 10,500\end{array}$ & With parents & $\begin{array}{l}\text { 1:1 support person } \\
24 \mathrm{hr}\end{array}$ & $\begin{array}{l}\text { Answered with words and phrases; direct verbal } \\
\text { prompts required; parent assisted in asking } \\
\text { questions/deciphering answers }\end{array}$ \\
\hline 3 & 24 & Autism & M & White & $\begin{array}{l}\text { MD/city, } \\
23,000\end{array}$ & With parents & $\begin{array}{l}\text { Semi- } \\
\text { independent (e.g., } \\
\text { drives car). }\end{array}$ & $\begin{array}{l}\text { Answered in sentences; indirect verbal prompts } \\
\text { required }\end{array}$ \\
\hline 4 & 35 & Autism & M & White & $\begin{array}{l}\text { MA/city, } \\
44,000\end{array}$ & $\begin{array}{l}\text { Assisted in } \\
\text { apartment or } \\
\text { house }\end{array}$ & $\begin{array}{l}1: 1 \text { support } \\
\text { person } 24 \mathrm{hr}\end{array}$ & $\begin{array}{l}\text { Answered with words and phrases; verbal } \\
\text { prompts required; support person assisted }\end{array}$ \\
\hline 5 & 41 & $\begin{array}{l}\text { Cognitive } \\
\text { disabilities }\end{array}$ & M & $\begin{array}{l}\text { African } \\
\text { American }\end{array}$ & $\begin{array}{l}\text { KS/city, } \\
100,000\end{array}$ & $\begin{array}{l}\text { Assisted in } \\
\text { apartment or } \\
\text { house }\end{array}$ & $\begin{array}{l}\text { No support at } \\
\text { night; } 2: 5 \text { staffing } \\
\text { ratio days }\end{array}$ & $\begin{array}{l}\text { Answered in sentences: indirect verbal prompts } \\
\text { required }\end{array}$ \\
\hline 6 & 33 & $\begin{array}{l}\text { Cognitive } \\
\text { disabilities }\end{array}$ & M & White & $\begin{array}{l}\text { KS/city, } \\
100,000\end{array}$ & $\begin{array}{l}\text { Assisted in } \\
\text { apartment or } \\
\text { house }\end{array}$ & $\begin{array}{l}1: 3 \text { support person } \\
\text { required } 24 \mathrm{hr} ; 2: 3 \\
\text { staffing ratio }\end{array}$ & $\begin{array}{l}\text { Answered in sentences; indirect verbal prompts } \\
\text { required; support person assisted }\end{array}$ \\
\hline 7 & 38 & $\begin{array}{l}\text { Cognitive } \\
\text { disabilities }\end{array}$ & M & White & $\begin{array}{l}\text { KS/city, } \\
100,000\end{array}$ & $\begin{array}{l}\text { Assisted in } \\
\text { apartment or } \\
\text { house }\end{array}$ & $\begin{array}{l}\text { No support } \\
\text { person required at } \\
\text { night; } 2: 5 \text { staffing } \\
\text { ratio days }\end{array}$ & $\begin{array}{l}\text { Answered in words and phrases; direct verbal } \\
\text { prompts required }\end{array}$ \\
\hline 8 & 45 & $\begin{array}{l}\text { Cognitive } \\
\text { disabilities }\end{array}$ & M & White & $\begin{array}{l}\text { KS/city, } \\
100,000\end{array}$ & $\begin{array}{l}\text { Assisted in } \\
\text { apartment or } \\
\text { house }\end{array}$ & $\begin{array}{l}\text { Support person } \\
\text { required } 24 \mathrm{hr} ; 2: 3 \\
\text { staffing ratio }\end{array}$ & $\begin{array}{l}\text { Answered in sentences; direct verbal prompts } \\
\text { required: support person assisted }\end{array}$ \\
\hline 9 & 20 & $\begin{array}{l}\text { Cognitive } \\
\text { disabilities }\end{array}$ & $\mathrm{F}$ & White & $\begin{array}{l}\text { KS/city, } \\
100,000\end{array}$ & $\begin{array}{l}\text { Assisted in } \\
\text { apartment or } \\
\text { house }\end{array}$ & $\begin{array}{l}\text { No support person } \\
\text { required at night; } \\
2: 5 \text { staffing ratio }\end{array}$ & $\begin{array}{l}\text { Answered in sentences; minimal verbal prompts } \\
\text { required }\end{array}$ \\
\hline
\end{tabular}


was set. Of the 4 participants in the focus group comprising individuals with autism, 7 lived independently, 1 lived semi-independently, and 2 required more support. The semi-independent participant. for example, lived with his mother and was dependent on her for meals, laundry, and budgeting. He was, however, employed (without a job coach), licensed to drive a car, and able to access public transportation independently. The two participants requiring more support were described by their support persons as "emerging into independence," a categorization that described the expectations they held. Although both preferred to communicate through a trusted support person (i.e., focus group questions were repeated by the support persons to the participants and/or responses were communicated by the participants to the group or quietly to the support providers, who relayed them to the group), 1 participant owned a small computer graphics/design business and the other traveled widely, making frequent speaking appearances at disability conferences. Focus group size was purposefully kept small to accommodate the communication needs of persons with disabilities.

Participants were also required to meet two screening criteria: (a) be a minimum of 13 years old, and (b) have engaged in problem behavior in the last 12-18 months. Problem behavior was defined as any serious episode of the type that required direct intervention such as physical restraint to prevent serious damage to self, others, or property. Examples included (a) selfinjurious behavior--hurting oneself by banging, hitting, biting, or ingesting foreign, nonedible substances: (h) physical aggressiveness--hurting others by hitting, choking, pulling hair, or biting; and (c) property destruction--destroying furniture, clothes, or objects.

Participants were recruited in two ways. For the first group, comprising individuals with cognitive disabilities and problem behavior, researchers contacted the board of directors (behavioral scientists at a local university) of a local adult service agency, explained the study's purpose and requested help in accessing participants. After approving the study, the board created a pool of appropriate participants (i.e., those that met the screening criteria) and arranged for the researchers to explain the study to the agency's human subjects committee and to the guardians of identified potential participants. From the group of 12 that submitted consent forms, researchers and agency board members used purposive sampling: (that is, the selection of a reduced number of respondents who represented diverse characteristics of the target group to select the 5 participants (Bogdan \& Biklen. 1982: Lincoln \& Guba, 1995). Diversity included (a) living situation, (b) gender, and (c) age. Researchers recruited members for the second focus group, comprising persons diagnosed with autism and problem behavior, with the assistance of The National Committee on Autism. Because this focus group was held during the annual conference of The National
Committee on Autism, this group was composed of both local registrants (from the greater Washington, DC area) as well as registrants traveling to the conference from different urban and suburban areas of the country. Researchers received permission from conference organizers to include a flyer in the conference registration packets advertising the study and requesting focus group participants. At the opening session, the conference chairperson announced the focus group, introduced the researchers, and directed interested conference attendees to register with researchers seated in the rear of the room. At the end of the opening session and during the first day of the conference, researchers met individually with interested attendees (i.e., persons with autism and/or persons with autism and their support persons) to further explain the purpose of the study and to determine if the interested attendee met the screening criteria. From this pool of 10 attendees researchers again used purposive sampling and chose 4 participants who met the screening criteria and were diverse in the following respects: (a) living situation, (h) gender, (c) age, and (d) geographical residence. Participants were offered the option of attending the focus group alone or attending with a support person they knew and trusted. Two support persons attended each focus group (Table 1). In addition to supporting the morale of the persons with disabilities they accompanied, support persons also were able to clarify vocalizations often spoken softly to support providers that were not otherwise readily understandable.

\section{Data Collection}

Researchers involved in the data collection process established rapport with participants before the focus groups began. For participants in the focus group comprising individuals with cognitive disabilities, the primary researcher met all participants individually at their homes and (a) spent 30-60 min getting to know the individuals (Malik, Ashton-Schaeffer, \& Kleiber, 1991; Taylor, Bogdan, \& Lutfiyya, 1995; Taylor \& Bogdan, 1998), and (b) explained the purpose of the study. In the focus group with individuals with autism, researchers accomplished the same tasks through 10min individual meetings and a 20-min group introductory "get-to-know-you" period that immediately preceded the focus group.

The two, 90-min focus groups conducted over a 5month period were completed by a team of two researchers and one doctoral student. One researcher served as bcus group moderator, and the other researcher and doctoral student served in support roles. Moderators for both focus groups were researchers and family members of individuals with significant disabilities. As such, they were experienced in interacting with individuals with communication difficulties (e.g., they spoke clearly and simply, allowed participants sufficient time to respond, and attended to participants' body language). The doctoral 
each focus group to operate an audiocassette recorder, keep track of time, and, along with the second researcher, take accompanying notes. To provide consistency for this study and for the larger research project of which this study was a part, the principal researcher moderated or acted as support researcher at both focus groups in this study and at all 12 focus groups of which this study was a part. In addition, researchers encouraged the participants to feel "at home" by enabling them to attend with support providers if they chose to, providing food and drink (orders were taken as the focus groups commenced), spending adequate time with introductions, and remaining sensitive to participant body language throughout the focus groups. Participants were oriented regarding restrooms and areas to smoke, and were encouraged to move about freely. In the focus group comprising individuals with cognitive disabilities, participants chose the location of the focus group. The focus group comprising individuals with autism was held in the conference hotel.

The interview guide (Table 2) grew directly from the research questions and set the general direction for the focus group discussion. In addition, a series of probes or sub-questions were generated to take into account the unique contributions that participants of this stakeholder group could make. The sub-questions were submitted to the study's advisory group as well as to the directors of the adult service agency from which participants for one of the focus groups were drawn. The questions took into account the cognitive abilities of the participants using methods described in the literature (Biklen \& Mosely, 1988; Dattilo, Hoge, \& Malley, 1996; Dent, 1986; Finlay \& Lyons, 2002; Malik et al., 1991; Perlman, Ericson, Esses, \& Issacs, 1994). Researchers, for example, used a combination of open-ended and closeended questions, kept sentences simple, and asked for examples as often as possible as a way of checking for participants' understanding of the question. Although the research questions and the interview protocol were used as a general guide, participants were encouraged to address issues and concerns most important to them. The overarching purpose of the study was for participants to discuss their priority interests regarding their lives and problem behavior, rather than to simply follow the researchers' questioning guide in a lockstep manner (Taylor \& Bogdan, '1998). After the first focus group was completed, the three-person research team met on a regular basis to discuss emerging themes, which were later used, when appropriate, as general probes. All focus groups were tape recorded and transcribed. Whenever possible, followup interviews were conducted to clarify statements made or to elicit more detail.

\section{Data Analysis}

Researchers used a transcript-based, constant comparative method of data analysis for this study (Glaser \& Strauss, 1967; Krueger, t994; Miles \& Huberman, 1994). This involved reviewing all field notes that included discussion points initiated or emphasized by participants, cogent quotes considered potentially illustrative of

Table 2

Interview Guide

I. Setting the context

A. Briefly introduce yourselves.

B. Tell your name and tell us one other thing about yourself (e.g., what you like to do, where you live, with whom you live

II. Your best days (research questions I and 2)

A. Describe a day in your life. What do you enjoy? What parts of the day/activities are important for you? Please describe.

B. Try and remember a clay that was a really good day, a day when everything went great. Tell about that day.

C. Tell about a clay that you are looking forward to.

III. Your dislikes and your poor days (research questions $t$ and 2)

A. What is one thing that you have a hard time tolerating'? What really bothers you'? Are there people, situations, smells, sounds, feelings, textures that are difficult for you to tolerate'? What do other people do that you really don't like? Please describe.

B. Can anyone describe poor days they have had (and behaviors that might be associated with poor days). (For example, days when you're tired, days when things don't work out like you thought, days when you end up getting mad and shouting at someone, pushing someone, throwing something, refusing to do something.)

C. Remember a day that wasn't so good. Remember a day when things didn't go right and you ended up getting a little upset. Has anyone here had a day like that'? Would anyone be willing to say something about one of their poor days'? Please describe that day or time.

IV. Problem behavior (research questions I and 2)

A. Facilitator gives examples of problem behavior (e.g., aggression to self, aggression to others, property destruction, pica.) Has anyone had a behavior like these'? Please describe.

B. Do you feel comfortable talking a little bit about a day on which such a behavior occurred? Can you remember a situation in which you were out of control, very angry or upset? Please describe.

V. How you learn (research question 3)

A. What is one skill that you have learned and that you are proud of? Please describe.

B. What is one activity in your life that you have learned to be in charge of? Please describe.

C. How do you learn best? Please describe.

D. Have you learned to be responsible for your behavior? Please describe. 
emerging themes, and important observations such as silent agreement or indications of group mood. It also involved reviewing summaries of debriefing sessions, and transcripts from each focus group. The principal researcher and a designated second researcher first read and analyzed data separately, then met to discuss discrepancies and to reach consensus. This analysis was purposefully systematic and involved established techniques including (a) organization and reduction of raw data, (b) generation of categories and codes, and (c) interpretation of patterns and themes (Knodel, 1993; Krueger, 1994; Miles \& Huberman, 1994; Merriam, 1998; Seidman, 1991; Stewart \& Shamdasani, 1990). The transcripts generated 8091 lines of text that were divided among 4 code categories and 21 subcode categories. The 4 code categories were (a) barriers-factors that hinder or restrict persons with dis abilities and problem behavior (and/or their parents, teachers, or support persons) from achieving reductions in problem behavior and increases in quality of life (comprised approximately $30 \%$ of coded data); (h) solutions-elements that, when addressed, improve the quality of life and improve the likelihood that problem behavior will be reduced or eliminated (comprised approximately $42 \%$ of coded data); (c) practices-descriptions of what is either in existence or are desired practices related to persons with problem behavior (comprised approximately $19 \%$ of coded data); and (d) information-information types, formats, and sources that were found to be useful (comprised approximately $9 \%$ of coded data). The process of physically organizing the data was facilitated by The Ethnograph, a computer software program capable of organizing and retrieving focus group data (Seidel, Friese, \& Leonard, 1995).

Researchers ensured the soundness of the research methodology by following procedures outlined by Lincoln and Guba (1985) as well as others (Brotherson \& Goldstein, 1992; Creswell,1994; Denzin, 1978; Marshall \& Rossman,1995; Maxwell, 1996; Miles \& Huberman, 1994; Patton, 1990). Principal among these procedures were (a) triangulation, (h) peer debriefing, (c) negative case analysis, (d) member checking. and (e) conducting a formative confirmatory analysis.

Triangulation in this study involved the use of multiple and different sources, methods, and investigators. In collecting data from 9 purposefully chosen participants, researchers hoped they would provide contextual validation. In addition, researchers used both focus groups and individual interviews as well as multiple investigators as ways of ensuring credibility. Although the lead researcher was present at both focus groups and interviews and provided consistency across the study, the second researcher and doctoral student, by checking the data analysis procedures. added to the probability that the data were accurate and that the findings would be found credible.
Peer debriefing took place immediately after each focus group among the three-member research team. During these sessions the research team discussed key issues or themes that emerged, any significant changes in the questioning process, disagreements or varying opinions about an issue, unexpected findings, overall mood, and usefulness of the focus group guide and questions. In addition, researchers met systematically with outside peer reviewers (university researchers with recent peer reviewed publications using qualitative methodology), who read portions of the transcripts to provide credibility and transferability of interpretations. Finally, peer review was provided by a qualitative research group that met regularly at the center where the study was conducted. The primary purposes of this group were to offer feedback on research methods proposed for individual studies and to establish centerwide research procedures considered critical in ensuring sound research methods.

The two principal researchers conducted negative case analyses by separately examining all uncoded chunks of data that did not fit any coding category. Each of the two researchers was satisfied that all negative cases ( $15 \%$ of total data) were not examples that would cause the coding rules to be broadened. Rather, these cases represented chunks of data that were lacking interpretable content, were moderator comments, or were participation prompts or probes.

Member checks were conducted at the conclusion of each focus group by summarizing the key questions and major ideas that emerged from the discussion and by asking participants if the summary was adequate, and/ or if any important issues had been missed.

Researchers conducted a formative confirmatory analysis by constructing and organizing a labeled paper trail of relevant materials as a method for ensuring soundness. These materials included notated transcripts, a decision diary documenting when and why decisions were made, and final results. An outside researcher with recognized expertise using qualitative inquiry reviewed the paper trail at each of the three phases of data analysis (i.e., organization and reduction of raw data, generation of codes and categories, and interpretation of themes) and confirmed the overall soundness of the research process. Suggestions made and incorporated included increasing the context (i.e., the number of lines) for particular coded data chunks, double-coding particular data chunks at the data organization and reduction phase, and increasing the amount of detail at the interpretation phase.

The findings identify the major themes that emerged within and across both focus group discussions and individual interviews.

\section{FINDINGS}

Findings from this study will be discussed according to the three research questions: (a) conditions/barriers, (b) solutions, and (c) informational strategies. 


\section{Research Question 1: What Do You Believe Are Some of the Conditions/ Barriers That Caused the Behavioral Challenges You Have Experienced?}

Individual's statements concerning conditions that adversely affected them can be categorized into three areas:. (a) communication difficulties, (b) environmental dislikes, and (c) programs. (See Table 2 for questioning guidelines.)

\section{Communication Difficulties}

Participants described having difficulties communicating appropriately in a variety of situations. Some participants tied their difficulties in communicating appropriately to frustrations and problem behaviors. For example:

Moderator: Can you describe a time to us when you just had a particularly hard time, where things weren't going well for you? Where it seemed like you just were getting in trouble or having problems getting along?

Participant 1: Like getting upset when some of my people talk angry at me ... which was like when I deliver mail, I have a hard time finding the buildings and room numbers, and I was trying to ask somebody where the room number was, which was a person I was looking for, and they were busy on the phone and they couldn't talk, so I got real upset and yelled at them. So one of my co-workers came out there and talked to the police and to [the company administrator].

Participant 2: You know what they're saying now, that behavior is communication. I really believe that now, because I was doing stuff like that [behavior of pulling one's own hair and eating it] when my mother was remarried ... I hated my stepfather.

Other participants were less clear in linking their language abilities to problem behavior. Instead, they described or demonstrated ways in which they had learned to cope with auditory stimulation and other sensitivities. One participant, for example, listened to opera via headphones and portable compact disk player during the focus group as a method of filtering out the unwanted background sounds of focus group participants talking. Another participant who experienced difficulty in processing auditory information during the focus group asked through her support person that the conversation be slowed down so she would be able to follow. Still another participant, distracted during the focus group by disturbing remembrances of abuse that occurred a number of years earlier, asked to vocalize her distraction. After her support provider provided background information on the persistence of these remembrances and of how vocalizing them would allow her to continue in the focus group, he asked permission of the group for her to share her distraction:
Participant: I do want to talk about something else. He's (the perpetrator) gone, he's out of here. He isn't gonna hurt me anymore.

Support person: That's right, he isn't.

Participant: He's gone. He's out of here.

Moderator: He's not going to hurt you anymore?

Participant: He's gone. He's out of here.

Support person: That's right. That's one of the interfering thoughts you've been having today.

Participant: He's gone. He's out of here.

Support person: That's right.

Participant: He's gone. lie's out of here.

Support person:... It's something you felt you had to say, to get it out of your mind.

Participant: That's right. Had to say.

\section{Environmental Dislikes}

Participants described strong dislikes of certain environmental conditions. Although some participants mentioned being disturbed by the lightning and thunder associated with severe weather, others described in detail how the nature of their living arrangement impacted their quality of life. Those not living independently described both their current and past living situations, and the extent to which these situations placed limits on their personal freedom and privacy.

\section{Personal freedom}

Limitations placed on personal freedoms seemed to vary based on the restrictiveness of the living situation. At the time the focus groups were conducted, participants lived either with their parents, independently, or in apartment-based assisted-living situations (see Table 1). Although participants did not complain about their current living arrangements, they did describe limitations on their freedom that seemed to be caused by changes or delays in their schedules involving preferred activities and by living with roommates and staff, not chosen, but assigned. One participant who lived in an assisted-living apartment with two other men described not being able to leave his apartment in the morning until the staff arrived to shut off the alarm:

Participant: We can't do it [turn off the alarm].

We'll get in trouble.

Moderator: Maybe you could learn to turn the alarm off yourself..

Participant: I don't know how to read.... I can't go out of the apartment; we get in trouble.

Other participants described being bothered by other circumstances in their apartment living situations. One participant, for example, described the radio being played too loud. A second participant described his dislike for the telephone that he said rang constantly. A third participant described how he needed to go to his room to escape his housemate talking, and a fourth participant described how he disliked taking orders: 
Participant: It's people like, saying that [pause] ordering me around. Tellin' me what to do. Especially when $\mathrm{C}$. [a staff member in whom the participant has established trust] is not here. When C. doesn't stop 'em [other people in his apartment].

Only I of 12 participants was able to drive. Many of the other participants described limitations on being able to travel either locally or out of town. Although participants did not equate not being able to travel when and where they liked with friendship development, one participant did describe not being able to see his cousins (who live 30 min away) as often as he would like. Another participant described little contact with his sisters and mother who lived in the same town. A third participant described wanting to travel to a resort city, a 3- to 4-hr drive:

Moderator: You mentioned [resort city], about taking a vacation down there.

Participant 1: Well, I wish B. and G. [program administrators] would work on that.

Moderator: So, it' you had your dream come true ...

Participant 1: If I could go to [resort city], and go see Johnny Cash, Merle Haggard, Buck Owens, Roy Clark, Grandpa Jones, Minnie Pearl ...

Moderator: Would that make you happier than you are now?

Participant '1: I'd be a lot happier if I went to [resort city], if I got away from [the town where participant I lives], cause it's not the people. 1 just would like to get away from the whole situation.

Several participants had previously lived in institutions. In contrast to their descriptions of the mild annoyances endured in their current community living situations, participants were extremely critical of limitations placed on their freedom in institutions:

Participant: I didn't like livin' there because, I had, I didn't have my own freedom. I didn't have my own, my own place to live. I was, I had to be around other people, and I don't like to be around other people.

Moderator: OK.

Participant: And then they wouldn't let me have a job. They wouldn't let the go out and work. They wouldn't let me do things on my own.

Moderator: OK.

Participant: I wanted to do things by myself. And they wouldn't let me have freedom, and that's what kind of made me mad. You know what I'm sayin'?

Moderator: Yeah, I hear what you're sayin.'

Participant: And they wouldn't let me like go and see B. and G. [relatives, and that really pissed me off. Because, if I wanna, it's, it's my business man, if I wanna see B. and G. see, see, that's, see that's my business. Nobody can take that away from me.

Moderator: So when you were living in those places, you didn't get too much of a chance?

Participant: No, I didn't, I didn't get [pause] no freedom. They wouldn't, they wouldn't, they wouldn't even leave me alone. They wouldn't let me read, they wouldn't let me do anything. And that kind of made me mad.... I don't like it when people like say that I can't do what I want to do. I say, "Hey! Don't tell me what to do. You ain't my mother. I'm a grown man."

Another less verbal participant described an institution's isolation booth where he had been placed as being "all dark." He further described it by pointing to a closet and to the peephole in the outside hotel door.

\section{Privacy}

As with personal freedom, participants described how privacy is important for them. One participant had a sign, "No Entry," on his bedroom door. Another participant described how he liked to go to his bedroom when he was upset. Participants also described how their privacy was limited when they lived in institutions, and how they continue to be upset when their privacy is violated:

Moderator: Is there anything that makes you upset in your apartment? Is there anybody that lives with you that ...

Participant 1: When G. [housemate] comes in my room, then 1 get upset.

Moderator: You didn't like people coming in your room [is cut off by participant 2] ...

Participant 2: No, I don't like people comin' in my room and tellin' me what to do, sayin,' "Well, you should do this, and you should do that [mimics authoritarian voice]." I said, "Hey, hey, now stop! Don't tell me what to do (voice becomes emotional), please! That makes me mad."

\section{Programs}

Participants were critical of particular programs. As previously discussed, participants had nothing positive to say about their lives in institutions. One participant also questioned portions of his current community program. He described how staffing his apartment did not meet his individual needs:

Moderator: Did you meet any friends since you moved to [name of his city]?

Participant: Well, I know, I been around N. [support person] too much. I just [pause], see, I see N. every day, and 1 get real sick of seein' N. most every day. 1 want to see different people besides him all time, cause I see him most every day, and, 
I get tired of seeing him most every day. I want to see different people.

\section{Research Question 2: What Do Individuals With Cognitive Disabilities and/or Autism Believe It Would Take to Build Practical, Positive Solutions to the Complex Behavioral Challenges They Face?}

Individuals statements regarding solutions can he categorized into four areas: (a) quality of life, (b) other environmental adaptations and accommodations, (c) teaching and learning, and (d) outside support.

\section{Quality of Life}

Although all solutions suggested by participants ultimately relate to quality of life, for purposes of this dis cussion, quality of life includes the following areas: (a) employment, (b) living situations, (c) recreation and leisure preferences, (d) relationships, and (e) self-help.

\section{Employment}

All participants talked about the importance of working. Eight participants had jobs, and 7 of the 8 worked in community settings. Participant 9 was looking forward to beginning a job in the near future. That work seemed to play an important role in participants' lives was evidenced by the number of statements made regarding work, some of which were completely unprompted. For example, several participants chose their work as the answer to the introductory question, "Introduce yourself by telling us one thing about yourself that you would like us to know." One participant described his work as "stupendous," and went into a significant amount of detail in explaining all of the different machines he was qualified to run at the recycling center where lie worked.

Work seemed to play an important role in participants' lives for at least two reasons: pay and recognition. Participants described not only that they worked, but also that they got paid. In addition, several participants knew when they got paid:

Participant 1: 1 work at [name of adult agency].

Moderator: Oh, you work at [name of adult agency].

Participant 1: I make money for that.

Moderator: Well, good.

Participant 1: 1 get my paycheck next week.

Participant 2: 1 get my check, I cash it at [name of local grocery store] ...

Moderator: You cash your check at [name of local grocery store]?

Participant 2: Yeah. Going to work tomorrow. Going to cash my check tomorrow.

Other participants relished receiving recognition as employees:

Participant: They [employer and work supervisors] have a lot of good things to, to [pause] people have a lot of good things to say about [participant. This is what [support person] told me, he said, "You know what (work supervisor) said about you, he said you're (lie hardest workin' man he knows. . . The [participant] is such a good guy, he's polite and all, and I think [participant] is such a great guy, he's such a hard workin' man" Oh, that made me feel good.

\section{Living situations}

Living situations were also important for participants. Those who had previously lived in institutions were clearly able to distinguish quality of life differences:

Moderator: So what made the difference between [names the institution] and where you currently live?

Participant: What's the difference?

Moderator: Yeah.

Participant: Because I have my own place, I have my own, um, I have my own place, I have my own apartment. I can talk to people. I talk very politely.... I can do what I want to do. Go play basketball, go lift weights, and they wouldn't let me do that hack, back when I was livin' out at [names institution], or [names institution], that nasty place ... and [institutional staff person] kept flapping her jaws all the time and I, I don't like it when people like say that I can't do what want to do. I say, "Hey, don't tell me what to do. You ain't my mother. I'm a grown man."

Other participants described enjoying their bedrooms in various ways. One participant listened to mu sic and entertained friends in her bedroom, another rode his exercise bike in his room, while a third enjoyed his room for undisturbed time alone from his housemates. Although it is unclear if participants would have chosen to live alone, limitations placed on personal freedom by housemates assigned, not chosen, were clearly a source of irritation among participants.

\section{Recreation and leisure preferences}

Participants described a large variety of preferred activities that they enjoyed on a regular basis. These ranged from watching westerns on television and stepping outside the apartment for a cigarette to going line dancing at a local country and western dance hall. Although one participant described wanting to go on vacation to a resort and not yet being given the permis sion to do so, another participant described flying to New York state to attend the wedding of a friend and former support person.

Participants valued being in charge, not only of recreation and leisure activities, but also of day-to-day routines that might also be classified as leisure activities. In describing what he did the first thing every 
morning, one participant described getting his own coffee:

Moderator: Do you know what you're going to

do when you wake up in the morning?

Participant: Going to get me coffee.

Moderator: You do that on your own?

Participant: Yep.

\section{Relationships}

Participants described the importance of relationships with three groups of people: (a) family, (h) support persons, and (c) other persons with disabilities.

Family. Whether participants still lived with family members or not, those who contributed comments on this theme recounted family relationships as being important. One participant who still lived with his mother described how she helped him with strategies he could use when lie became upset. Another participant described wanting more contact with his cousins and how he missed his deceased parents:

Moderator: So what would be one of your dreams then? For a perfect life, what would your dreams be'?

Participant: Oh, just sayin' to my mom and dad, how much I love 'em.

Moderator: Havin' them back ...

Participant: I just wish one day, I wish one day in my life if I had my parents here, things would go a lot better.

Support persons. Relationships with support persons were valued by participants. They described various outings with support persons including trips to local convenience stores and the movies. One participant explained that it was important for him to have good friends to whom he could go for support, while another participant described the importance of having others believe in her abilities:

Participant: We [at work] have a wonderful new director, [director] is just wonderful. My duties are becoming more interesting. I feel sothe people I work with now really believe in what I'm doing and believe in me. So I'm starting to believe in myself.

Persons with disabilities. Participants described various activities with friends, which included watching movies, listening to music, talking on the phone, and just "hanging out." Two participants described relationships as having reached a deeper level. One participant described an outing with a friend as a "date." Another participant described having an out-oftown girlfriend that lie loved:

Participant: I've got a girlfriend, [girlfriend's name].

Moderator: So you like hanging out with [girl friend's name]?... Tell me what you do with [girlfriend's name]?

Participant: She's my girlfriend and I love her, too.

Moderator: What do you two do together?

Participant: We talk on the phone.

Moderator: Do you talk on the phone every day?

Participant: Nope, not every day, we can't. Just on Sundays. Not on Saturdays.

Moderator: Not on Saturdays, OK. Do you two ever go out?

Participant: [girlfriend's name] lives too far from here.

Moderator: Oh, she lives out of town?

Participant: Yeah.... I call her, and after she calls me back.

In contrast to one participant who described the irritation of living with housemates who were chosen for him and did not respect his privacy, two participant housemates had developed a trusting relationship with one another. One of the two experienced seizures and relied on his housemate to check on him at night and call 911 if an emergency occurred:

Moderator: Tell me a little bit about your friends [participant's name]. Do you have anybody that you would call a friend'?

Participant: [names his housemate].

Moderator: [housemate] is your friend. Why is [housemate] your friend?

Participant: Opens the door at night. Checks on me ... [housemate] opens the door. Helps me when I have seizure.

Support person: [participant] said a few days ago that lie feels real secure at night because there is no staff person here at night. So if [participant] has a seizure, [housemate] will call 911.

Although the reason one participant became irritated by his housemates and another developed a trusting relationship is not clear, it may be that the restrictiveness of the living situation or severity of problem behavior played a role. The participant that described being irritated by his housemates lived in a group home with 24-hr support (2 staff persons to 3 individuals with disabilities [see Table 1]) specifically designed for individuals with severe problem behavior, whereas the man who described his trusting relationship lived in a group home where less support was needed ( 2 staff persons to 5 individuals with disabilities).

\section{Self-help}

A last factor that added to participants' increased quality of life was the ability to help oneself. All participants commented on how having jobs and earning money was important to them. One particularly articulate participant described her positive orientation to 
self- improvement:

Moderator: What do you think is helping you get better?

Participant: Just thinking I can get better, I can improve, I can use my brain to manage my brain. We don't tap into half of our brain's potential, and there's a lot there that's being unused. And if I think of that, I feel as though I can keep continually growing and changing all the time.

Another participant described a positive sense of self-awareness and willingness to work to better himself:

Participant: And I've got real good by being polite to everybody. I know it's kind of hard to do sometimes. 'Cause I know I have a hard time being polite, but I'm tryin', tryin' my best to be polite to everybody.

Moderator: Are you feeling pretty good about yourself'?

Participant: Yeah, I am. I feel real good that I have a job (pause) that I can stand on my own two feet, that I don't need, I don't need nobody to ... [pause] ... I know I don't always need somebody to do things for me all the time. I can do things for myself, like I asked for the keys to my own workshop, and they [his bosses at large retail chain store] said they're goin' to get me some keys.

There is a suggestion, at least, that the ability to feel good about oneself and help oneself is linked to other factors described in this section, that is, employment, living situations, recreation and leisure, and relationships. Of the 2 participants who specifically commented on helping themselves, both were very satisfied with one or more of these factors, and seemed to be satisfied with themselves.

\section{Other Environmental Supports}

In addition to the more comprehensive quality of life improvements discussed above, participants also described time-limited environmental adaptations that helped them relax. These included therapies and other calming activities. Participants discussed the usefulness of several therapies including sensory integration, and brushing and compression therapies. Other activities described as calming included having a cigarette, working on cars, going to one's own bedroom, and listening to music. One participant found relaxation tapes helpful in allowing her to sleep at night.

\section{Teaching and Learning}

Participants also described teaching and learning as important in effecting solutions. One participant described effective teaching as beginning with an ability to listen:
Moderator: What does it take to really put together support for someone?

Participant: It really takes a lot of listening and understanding what the person really needs, what accommodations that person really needs, and how that person can best be helped.

This ability to listen and understand was described by a second participant. It was important for him that his support person was able to "read" his nonverbal gestures, know when he was mad, and initiate deescalating strategies. A third participant described respect as the critical ingredient in teaching:

Participant: And he (a teacher) doesn't go around and tell me what ... [pause] ... I can do this, I can't do that. He just like, asks me very politely.

Moderator: OK.

Participant: And me and him both work together.

Participants described learning a variety of skills from parents or support persons with whom they had established rapport. One participant had learned to communicate more effectively using facilitated communication; another used the computer to communicate and create freelance products such as invitations and announcements, and a third participant learned to accept criticism gracefully.

\section{Outside Support}

The two additional areas of flexible funding and research were each mentioned once as additional factors that aided in producing solutions.

\section{Flexible funding}

One participant who had achieved perhaps the most dramatic reductions in problem behavior and increases in quality of life described flexible funding as critical in her empowerment.

Support person: We've basically been battling a whole separate battle with advocacy of changing. You mentioned about changing the state system, I mean, basically, we've done it. [Participant's] been in the forefront. And we've actually got an independent voucher.... Now, [participant's] money is very flexible, and also, they're actually giving it to [participant] upfront.

Participant: Yeah, I get my money up front.

\section{Research}

Participants contributed only a small amount of information on the role of research and information. One participant suggested that researchers work to better understand the brains of persons with autism so their potential can be maximized:

Moderator: If you could get researchers to study certain questions, what would you ask researchers to study? 
Participant: Questions about how people with autism can adapt to their situation. My feeling is that because their brains have so much potential that's on tap, the cure is irrelevant. I think we just have to learn how to grow and change all of our lives, and we have to figure out how to help people with autism do that. To keep growing and to keep changing; learning and adapting.... Your brain, what shall I say, the ultimate mystery, the ultimate wonderful challenge. It's like the twilight zone that we really don't understand very well. And if we can delve into it more and learn about it, we can use this information to manage our brains, and we can figure out how to adapt, and how to adjust and what we need to do to change.... It [autism] isn't so much of a problem because, what's the opposite of deficit? Capability. For all the problems that people with autism have, flip the coin and "bang," you've got wonderful things, you've got creativity, you've got genius, you've got brilliance.

\section{Research Question 3: What Kinds of User-Friendly, Low-Cost Informational Products Do Individuals with Problem Behavior Believe Would Be Most Helpful in Solving Their Own Behavioral Challenges?}

In discussing the area of products and dissemination, individuals with disabilities commented in two areas: (a) information formats and (b) information sources.

\section{Information Formats}

Although 1 participant was able to read and suggested reading to gather information, all other format suggestions were oral. One participant described learning about money by playing money bingo. Other participants described learning appropriate social, vocational, and recreational skills by role-playing and modeling:

Participant 1: I learned to accept criticism.

Moderator: How did you learn to accept criticism?

Participant 1: By [first staff person], and [second staff person], and [third staff person].

Moderator: What did they do?

Participant 1: They give me criticism.

Staff: Do you want to run through one?

Participant 1: Sure.

Staff: Let me give you one. [Participant 1], your shoes are untied.

Participant 1: Oh really? I'm sorry. What could I do differently?

Staff: You could ask me to help you tie it again.

Participant 1: Oh really? I'm sorry. I didn't know, but thanks for telling me.
A second participant confirmed the modeling and practice format:

Moderator: How did they teach you?

Participant 2: Well, just like learning how to cast [fishing]. It took some teachin', but I worked on it. [Staff person] taught me how to do a lot of stuff.. How to get up in the mornin', take a shower, brush my teeth, unlock the door, how to work on cars ...

Moderator: Did he tell you or show you?

Participant 2: No, he showed me.... I like to be able to practice and have someone show me.

\section{Information Sources}

Although participants had limited comments on information sources, it appeared that they received information from those persons they knew and trusted. Participants who no longer lived at home talked a lot about various persons who provided them with support as helping them learn various social, vocational, and recreational skills. A staff person helped 1 participant with unclear verbal skills remember that university researchers had helped him learn not to become upset when persons could not understand what he said. Participants who still lived at home suggested their parents as information sources. A participant. with autism recommended physicians and psychologists as sources for information on autism.

\section{DISCUSSION}

The primary purpose of this research was to give voice to 9 participants representing individuals with cognitive disabilities and/or autism in an attempt to better understand their experiences and perceptions of current experiences, solutions, and informational resources that could be helpful in increasing quality of life and further understanding behavioral challenges in people with disabilities. Although care was taken in selecting a nationwide group of participants who met specific screening criteria, these participants may, in fact, not have accurately represented individuals with cognitive disabilities and/or autism. Participants with autism attending a national convention, for example, may not be representative of persons with autism as a whole. This may have resulted in important themes not emerging. Second, although the researchers purposefully collected only enough behavioral information to justify including participants in the study, more specific information on the level or amount of problem behavior, both past and current, may have added to the clarity of the study. Third, although care was taken to ensure the trustworthiness of this study (i.e., the data were read and analyzed separately by two researchers and their findings were later confirmed by a third researcher not involved in the study), it is possible that researcher bias may have influenced the identified findings. For example, all researchers involved in the study were family members of persons with disabilities. Although researchers' family members were not involved in this study, researchers' orientation as family members may have influenced the emergent themes. Last, it cannot be 
concluded that the factors described by the focus group participants were the factors that actually contributed to the problem behavior. Questions were not asked in such a way as to make this type of association. Similarly, we do not know if a similar group of' participants experiencing similar obstacles to a more selfdetermined lifestyle would necessarily also display problem behaviors.

\section{Key Themes and Recommendations}

Given the descriptive nature of this study and the limited number of participants, we were cautious not to draw definitive conclusions. However, two key themes emerged from our analyses.

\section{Quality of Life and Problem Behavior}

Further study of the relationship between comprehensive lifestyle change with a view to improving quality of life and problem behavior of individuals with dis abilities emerged as being worthy of further exploration. Quality of life is defined from the subjective standpoint of the individual (Brown, .1996; Felce, 1997: Gardner \& Nudler, 1999; Renwick, Brown, \& Nagler, 1996; Schalock, 1996, 1997, 2000; Turnbull \& Turnbull, 2000: Turnbull et al., 2000; Turnbull, BlueBanning, Turbiville, \& Park, 1999) and reflects outcomes for people rather than compliance with program process (Gardner \& Nudler, 1999: Turnbull \& Turnbull, 2001). Individuals with problem behavior and cognitive dis abilities and/or autism living in agency settings described how quality of life improvements were rarely individualized or reflective of outcomes they had chosen. Their lives seemed to be missing individualized personal outcome measures grounded in the principle of informed decision making. The emerging themes stressed the importance of (a) individuals with disabilities defining their own outcomes, (b) individuals with disabilities experiencing a range of options from which to make choices, or (c) organizations facilitating outcomes identified by individuals (Gardner \& Nudler, 1999). For example, participants discussed the frustrations of not being able to self-select apartments, housemates, and vacations. In this regard, 5 participants shared apartments with 2 or more housemates who were experiencing problem behavior. Participants also discussed their desire for increased social and friendship connections. Although individuals with disabilities living in agency-run group homes and apartments described improvements in various quality of life domains (in contrast to their earlier experiences in state institutions), the message they conveyed was that they wanted more control in determining their own quality of life outcomes. Indeed, individuals with problem behavior and cognitive disabilities and/or autism did not view themselves so much as behavior problems as they did individuals whose lives were missing these key critical elements that comprise individualized, comprehensive lifestyle support. The statements from this particular group of participants appeared to confirm their problem behavior as emerging from a background of exclusion, lack of personal control, and limited lifestyles.

If we agree with Carr et al. (2002) that, "the sine qua non of PBS is its focus on assisting individuals to achieve comprehensive lifestyle change with a view to improving quality of life not only for persons with dis abilities but also for those who support them." (p. 6), and that, "the reduction of challenging behavior per se is viewed as an important secondary goal that is of value principally because of its facilitative effect on producing meaningful lifestyle and cultural changes that are stable and enduring." (p.7), then it follows that the literature base documenting this new primary measure of outcome success (Hitzing, 1988; Horner, 1991; O'Brien, 1987) should be expanded. Emphasis needs to be placed on improvements in family life, employment, expanded social relationships, community inclusion, supported living, and personal satisfaction. Additional research that documents the effect of a coordinated, comprehensive effort to provide preference-based lifestyle support is necessary. By continuing to target individuals with disabilities, and their families and friends who have succeeded in creating such comprehensive support, much can be learned about practical, positive solutions.

\section{Giving Voice to Persons with Disabilities}

What became very clear in the process of conducting the two focus groups was that participants were passionate in talking about their lives and had much to say about how their lives could be improved. Participants described a quality life as including (a) employment that paid them a salary: (b) living situations that respected their right to privacy; (c) personal freedom and preferences; (d) the opportunity to learn skills requiring more responsibility, such as setting the house security alarm or operating new machines at work; (e) relationships with family, support persons, or other persons with disabilities; and (f) the resources necessary to make these things happen. The participants also recognized their need for support, and recommended that support be individualized and that they be given more direct control of support resources. Their statements suggested how infrequently their input regarding what they valued and considered important was either solicited or acted upon. A collaborative approach to supporting persons with disabilities and problem behavior must be founded on the fact that they are people first and have disabilities second. Although the basic needs of the participants in this study (e.g., food, clothing, shelter) were more than adequately met, many of their quality of life needs and unique needs as persons were unmet.

Consistent with the PBS approach (Carr et al., 2002), persons with disabilities, together with other relevant stakeholders (e.g., parents, siblings, neighbors, teachers, 
job coaches, friends, roommates, and other persons with disabilities), should play active roles in reciprocal research processes whenever possible. Persons with dis abilities should be given a voice in determining (a) whether suggested intervention approaches are relevant for the challenging situations that need to be addressed, and (b) whether the defined outcomes are likely to improve their quality of life. In this regard, increased emphasis should be placed on assessment practices such as focus groups or individual assessments to be able to further delineate personalized quality of life variables. If this study is any indicator, there is a clear suggestion that persons with disabilities are dis satisfied with their role as passive recipients and want more active involvement in and control over the intervention and support processes that involve them. Indeed, there was much wisdom in the words spoken during the course of these focus groups. We would be wise to heed the words of the young woman with autism who said, "I think we just have to learn to grow and change all of our lives ... to keep growing and to keep changing, learning and adapting ..."

\section{References}

Alberto, P. A., \& Troutman, A. C. (2003). Applied behavior analysis for teachers (6th ed.). Upper Saddle River, NJ: Merrill.

Biklen, S. K., \& Mosely, C. R. (1988). "Are you retarded?" "No, I'm Catholic": Qualitative methods in the study of people with severe handicaps. Journal of the Association for Persons with Severe Handicaps, 13, 155-162.

Billingsley, B. S. (1993). Teacher retention and attrition in special and general education: A critical review of the literature. Journal of Special Education, 27(2), 137-174.

Billingsley, B. S., Bodkins, D., \& Hendricks, M. B. (1993). Why special educators leave teaching: Implications for administrators. Case in Point, 7(2), 23-40.

Billingsley, B. S., \& Cross, L. H. (1991). Teachers' decisions to transfer from special to general education. The Journal of Special Education, 24(4), 496-511.

Billups, L.. H. (1997). Response to bridging the research-topractice gap. Exceptional Children, 63, 525-527.

Bogdan, R., \& Biklen, S. K. (1982). Qualitative research for education: An introduction to theory and methods. Boston: Allyn \& Bacon.

Bouma, R., \& Schweitzer, R. (1990). The impact of chronic childhood illness on family stress: A comparison between autism and cystic fibrosis. Journal of Clinical Psychology, 46, 722-730.

Brotherson, M. J. (1994). Interactive focus group interviewing: A qualitative research method in early intervention. Topics in Early Childhood Special Education, 14, 101-118.

Brotherson, M. J., \& Goldstein, B. L. (1992). Quality design of focus groups in early childhood special education research. Journal of Early Intervention, 16(4), 334-342.

Brown, R. 1. (1996). Quality of life issues for students and families. Proceedings of the Queensland Guidance and Counseling Association 9th Conference, Brisbane.

Bruyere, S. M. (1993). Participatory action research: Overview and implications for family members of persons with disabilities. Journal of Vocational Rehabilitation, 3, 62-68.
Carnine, D. (1997). Bridging the research-to-practice gap. Exceptional Children, 63, 513-521.

Carr, E. G., Dunlap, G., Horner, R. H., Koegel. R. L., Turnbull, A. P., Sailor, W., et al. (2002). Positive behavior support: Evolution of an applied science. Journal of Positive Behavioral Interventions, 4(1), 4-16.

Carr, E. G.. Horner, R. H., Turnbull, A. P., Marquis, J. G., Magito McLaughlin, D., McAtee, M. L., et al. (1999). Positive behavior support for people with developmental disabilities. Washington, DC: American Association on Mental Retardation.

Creswell, J. W. (1994). Research design: Qualitative and quantitative approaches. Thousand Oaks, CA: Sage.

Dattilo, J., Hoge, G., \& Malley. S. (1996). Interviewing people with mental retardation: Validity and reliability strategies. Therapeutic Recreation Journal, 30, 163-178.

Dent, H. R. (1986). An experimental study of the effectiveness of different techniques of questioning mentally handicapped child witnesses. British Journal of Clinical Psychology, 25, 13-17.

Denzin, N. K. (1978). Sociological methods. New York: McGraw-Hill.

DeVault, G., Krug, C., \& Fake, S. (1996). Why does Samantha act that way? Exceptional Parent, 26(9), 43-47.

Felce, D. (1997). Defining and applying the concept of quality of life. Journal of Intellectual Disability Research, 41, 126-135.

Finlay, W. M. L., \& Lyons, E. (2002). Acquiescence in interviews with people who have mental retardation. Mental Retardation, 40(1), 14-29.

Freedman, R. I., \& Fesko, S. L. (1996). The meaning of work in the lives of people with significant disabilities: Consumer and family perspectives. Journal of Rehabilitation, 62(3),49-55.

Gardner, J. F., \& Nudler, S. (1999). Quality performance in human services: Leadership, values and vision. Baltimore: Paul H. Brookes.

Geertz, C. (1973). Thick description: Toward an interpretive theory of culture. In C. Ceertz (Ed.), The interpretation of cultures. New York: Basic Books.

Glaser, B., \& Strauss, A. L. (1967). The discovery of grounded theory: Strategies for qualitative research. Chicago: Aldine.

Goode, D. A. (1986). Who is Bobby? Ideology and method in the discovery of a Down syndrome person's competence. In P. M. Ferguson, D. L. Ferguson, \& S. J. Taylor (Eds.), Interpreting disability: A qualitative reader (pp. 197-212). New York: Teachers College Press.

Goode, D. A. (1992). A world without words. The social construction of children born deaf and blind. Philadelphia: Temple University.

Hitzing, W. (1988). Community support for people with challenging behaviors. Presentation at Oregon Developmental Disabilities Conference, Eugene, OR.

Horner, R. H. (1991). The future of applied behavior analysis for people with severe disabilities. In L. Meyer. C. Peck. \& L. Brown (Eds.), Critical issues in the lives of people with severe disabilities. Baltimore: Paul $\mathrm{H}$. Brookes.

Horner, R. H.. Albin, R. W., \& O'Neill, R. E. (1996). Supporting students with severe intellectual disabilities and severe challenging behaviors. In G. Stoner, M. R. Shinn, \& H. M. Walker (Eds.), Interventions for achievement and behavior problems (pp. 269-287). Bethesda, MD: National Association of School Psychologists.

Kaestle, C. F. (1993). The awful reputation of educational research. Educational Researcher, 22(1), 23-31. 
Kaufman, M., Schiller, E., Birman, B., \& Coutinho, M. (1993). A federal perspective on improving practices, programs, and policies in special education. Evaluation and Program Planning, 16, 263-269.

Knodel, J. (1993). The design and analysis of focus group studies: A practical approach. In D. L. Morgan (Ed.), Successful focus groups: Advancing the state of the art (pp. 35-50). Newbury Park, CA: Sage.

Koegel, R. L., Bimbela, A., \& Schreibman, I. (1996). Collateral effects of parent training on family interactions. Journal of Autism and Developmental Disorders, 26, 347359.

Koegel, R. L., Schriebman, L., Loos, L. M., Dirlich-Wilhelm, H., Dunlap, G., Robbins, F., \& Plienis, A. J. (1992). Consistent stress profiles in mothers of children with autism. Journal of Autism and Developmental Disorders, 22, 203216.

Kornblet, A. (1997). Response to bridging the research-topractice gap. Exceptional Children, 63, 523-524.

Krueger, R. A. (1994). Focus groups: A practical guide for applied research (2nd ed.). Newbury Park, CA: Sage.

Lincoln, Y. S., \& Guba, E. 0. (1985). Naturalistic inquiry. Beverly Hills, CA: Sage.

Lincoln, Y. S., \& Guba, E. G. (1995). Emerging criteria for quality in qualitative and interpretive research. Qualitative Inquiry, 1(3), 275-289.

Lucyshyn, J., Albin, R., \& Nixon, C. D. (1997). Embedding comprehensive behavioral support in family ecology: An experimental, single-case analysis. Journal of Consulting and Clinical Psychology, 65, 241-251.

Lucyshyn, J., Olson, D., \& .Horner, R. H. (1995). Building and ecology of support: A case study of one woman with severe problem behaviors living in the community. The Journal of The Association for Persons with Severe Handicaps, 20, 1630.

Malik, P., Ashton-Shaeffer, C., \& Kleiber, D. (1991). Interviewing young adults with mental retardation: A seldom used research method. Therapeutic Recreation Journal, $25,60-73$

Malouf, D. B., \& Schiller, E. P. (1995). Practice and research in special education. Exceptional Children, 61, 414-424.

Markey, U. A. (2000). Partnerships. Journal of Positive Behavioral Interventions, 2, 188-189, 192.

Marshall, C., \& Rossman., G. B. (1995). Designing qualitative research (2nd ed.). Thousand Oaks, CA: Sage.

Maxwell, J. A. (1996). Qualitative research design: An interactive approach (Vol. 41). Thousand Oaks, CA: Sage.

Merriam, S. B. (1998). Qualitative research and case study applications in education. San Francisco: Jossey-Bass.

Meyer, L. Fl., Park, H. S., Grenot-Scheyer, M., Schwartz, I., \& Harry, B. (1998). Participatory research: New approaches to the research to practice dilemma. The Journal of The Association for Persons with Severe Handicaps, 23, 165-177.

Miles, M. B., \& Huberman, A. M. (1994). Qualitative data analysis: A sourcebook of new methods. Newbury Park, CA:Sage.

Mitchell, S. M. (1997). Response to bridging the research-topractice gap. Exceptional Children, 63, 533-534.

Morgan, D. L., \& Krueger, R. A. (1993). When to use focus groups and why. In D. L. Morgan (Ed.), Successful focus groups: Advancing the state of the art. Newbury Park, CA:Sage.

Morrissey, P. A. (1997). Response to bridging the research-topractice gap. Exceptional Children, 63, 531-532.
O'Brien, J. (1987). A guide to lifestyle planning: Using the Activities Catalog to integrate services and natural support systems. In B. Wilcox and G. T. Bellamy (Eds.), A comprehensive guide to The Activities Catalog (pp. 175-189). Baltimore: Paul H. Brookes.

Olney, M. F. (2001). Communication strategies of adults with severe disabilities: Supporting self-determination. Rehabilitation Counseling Bulletin, 44, 87-91.

Patton. M. Q. (1990). Qualitative evaluation and research methods. Newbury Park, CA: Sage.

Perlman, N. B., Ericson, K. I., Esses, V. B., \& Issacs, B. J. (1994). The developmentally handicapped witness: Competency as a function of question format. Law and Human Behavior, 18, 171-187.

Quire, L. (1986). Behavior problems in severely mentally handicapped children. Psychological Medicine, 16, 895907.

Renwick, R., Brown, L., \& Nagler, M. (Eds.). (1996). Quality of lfe in health promotion and rehabilitation: Conceptual approaches, issues, and applications. Thousand Oaks, CA: Sage.

Robbins, F., Dunlap, G., \& Plienis, A. J. (1991). Family characteristics, family training, and the progress of young children with autism. Journal of Early Intervention, 15, 173-184.

Ruef, M. (2001). Wie Personen mit Autismus und geistiger Behinderung das eigene Prohlemverhalten sehen-eine qualitative Untersuchung unter Einbeziehung von Fokusgruppen. Heilpaedagogische Forschung, 27, 158169.

Ruef, M. B., \& Turnbull, A.P. (2001). Stakeholder opinions on accessible informational products helpful in building positive, practical solutions to behavioral challenges of individuals with mental retardation and/or autism. Education and Training in Mental Retardation and Developmental Disabilities, 36, 441-456.

Ruef, M. B., Turnbull, A. P., Turnbull, H. R., \& Poston, D. (1999). Perspectives of five stakeholder groups: Challenging behavior of individuals with mental retardation and/or autism. Journal of Positive Behavioral Interventions, 1, 43-58.

Santelli, B., Singer, G. H. S., DiVenere, N., Ginsberg, C., \& Powers, L. E. (1998). Participatory action research: Reflections on critical incidents in a PAR project. Journal of the Association for Persons with. Severe Handicaps, 23, 211-222.

Schalock, R. L., (1996). Quality of life: Volume I. Conceptualization and measurement. Washington, DC: American Association on Mental Retardation.

Schalock, R. L. (t997). Quality of life: Volume II. Application to persons with disabilities. Washington, DC: American Association on Mental Retardation.

Schalock, R. L. (2000). Three decades of quality of life. In M. Wehmeyer \& J. Patton (Eds.), Mental retardation in the 21st century (pp. 335-356). Austin, TX: Pro-Ed.

Schubert, A. (1997). "1 want to talk to everyone": On the use of multiple means of communication. Mental Retardation, 35, 347-354.

Seidel, J., Friese, S., \& Leonard, D. C. (1995). The ethnograph V4.0: A user's guide. Salt Lake City, UT: Quality Research Associates.

Seidman, I. E. (1991). Interviewing as qualitative research: A guide for researchers in education and the social sciences. New York: Teachers College Press.

Silverman, G. R. (1992). New capabilities improve telephone focus groups. Orangeburg, NY: Market Navigation, Teleconference Network. 
Stewart, D. W., \& Shamdasani, P. N. (1990). Focus groups: Theory and practice (Vol. 20). Newbury Park, CA: Sage.

Sydoriak, D., \& Fields, M. J. (1997). Response to bridging the research-to-practice gap. Exceptional Children, 63, 529-530.

Taylor, S. J., \& Bogdan, R. C. (1998). Introduction to qualitative research methods:: A guidebook and resource (3rd ed.). New York: Wiley.

Taylor, S. J., Bogdan, R. C., \& Lutfiyya, Z. M. (1995) The variety of community experience: Qualitative studies of family and community life. Baltimore: Paul $\mathrm{H}$. Brookes

Turnbull, A. P., Blue-Banning, M., Turbiville, V., \& Park, J. (1999). From parent education to partnership education: A call for a transformed focus. Topics in Early Childhood Special Education, 79(3), 164-172.

Turnbull, A. P., Friesen. B. J., \& Ramirez, C. (1998). Participatory action research as a model for conducting family research. Journal of the Association for Persons with Severe Handicaps, 23, 178-188.

Turnbull, A. P., \& Ruef, M. B. (1997). Family perspectives on inclusive lifestyle issues for people with problem behavior. Exceptional Children, 63, 211-227.

Turnbull, A. P., \& Turnbull, H. R. (1996). Group action planning as a strategy for providing comprehensive family support. In L. K. Koegel, R. L. Koegel, \& G. Dunlap (Eds.), Positive behavioral support: Including people with difficult behavior in the community (pp. 99114). Baltimore: Paul H. Brookes.

Turnbull, A. P., \& Turnbull, H. R. (2000). Achieving "rich" lifestyles. Journal of Positive Behavioral Interventions, 2, 190-192.

Turnbull, A. P., \& Turnbull, H. R. (2001). Self determination for individuals with significant cognitive disabilities and their families. The Journal of the Association for Persons with Severe Handicaps, 20, 5662.
Turnbull, A. P., Turnbull, 1-I. R., Poston, D., Beegle, G., Park, J.. Reichard. A., et al. (2000, August). Family quality of life in the United States. Paper presented at the meeting of the International Association for the Scientific Study of Intellectual Disability, Seattle, WA.

U. S. Department of Education. (1998). Twentieth annual report to 'congress on the implementation. of the Individuals with Disabilities Education Act. Washington, DC: Author. (ERIC Document Reproduction Service No. ED 424 722)

Vaughn, B. J., Clarke, S., \& Dunlap, G. (1997). Assessmentbased intervention for severe behavior problems in natural family context. Journal of Applied Behavioral Analysis, 30, 713-716.

Vaughn, B. J., Dunlap, G., Fox, L., Clarke, S., \& Bucy, M. (1997). Parent professional partnership in behavioral support: A case study of community-based intervention. Journal of the Association for Persons with Severe Handicaps, 22, 185-197.

Walker, M. L. (1993). Participatory action research. Rehabilitation Counseling Bulletin, 37, 2-5.

Whyte, W. F., Greenwood, D. J., \& Lazes, P. (1991). Participatory action research: Through practice to science in social research. In W. F. Whyte (Ed.), Participatory action research (pp. 19-55). Newbury Park, CA: Sage.

Article received: October 16, 2001 Final acceptance: May 3, 2002 Editor in charge: Lynn Kern Koegel

This research was supported by a grant from the National Institute on Disability and Rehabilitation Research to the Beach Center on Disability, Grant \#H133B30070. 